\title{
Asymptomatic Submucosal Lipoma of the Anal Canal: A Report of an Incidental Colonoscopic Finding in an Elderly Patient with Colonic Diverticuli
}

\author{
Ikechukwu Bartholomew Ulasi ${ }^{1 *}$, Kolawole Oluseyi Akande ${ }^{2}$, Adegboyega Akere ${ }^{2}$, Oludolapo \\ Ola Afuwape ${ }^{3}$, Temitope Olufemi Oke ${ }^{3}, \mathrm{Omobolaji}_{\text {Oladayo Ayandipo }}^{3}$ and Moranike Adedoyin \\ Osundina ${ }^{4}$ \\ ${ }^{1}$ Department of Surgery, University College Hospital, Ibadan, Nigeria \\ ${ }^{2}$ Department of Medicine, College of Medicine, University of Ibadan /University College Hospital Ibadan, Nigeria \\ ${ }^{3}$ Department of Surgery, College of Medicine, University of Ibadan /University College Hospital Ibadan, Nigeria \\ ${ }^{4}$ Department of Medicine, University College Hospital, Ibadan, Nigeria \\ *Corresponding author: Ikechukwu Bartholomew Ulasi, Department of Surgery, University College Hospital, Ibadan, Nigeria
}

\section{ARTICLE INFO}

Received: 幽 October 19, 2021

Published: 慧 October 29, 2021

Citation: Ikechukwu Bartholomew Ulasi, Kolawole Oluseyi Akande, Adegboyega Akere, Oludolapo Ola Afuwape, Temitope Olufemi Oke, et al., Asymptomatic Submucosal Lipoma of the Anal Canal: A Report of an Incidental Colonoscopic Finding in an Elderly Patient with Colonic Diverticuli. Biomed J Sci \& Tech Res 39(4)-2021. BJSTR. MS.ID.006340.

Keywords: Anal Lipoma; Endoscopy; Colonic Diverticulosis; Submucosal Adiposis

\begin{abstract}
Background: Lipomas are benign adipose tissue tumours, very common in superficial locations. Deep-seated ones like those involving the gastrointestinal tract are uncommon and involvement of the anal canal is rare. We present an incidental finding of a submucosal lipoma of the anal canal in an elderly patient with colonic diverticulosis.

Case Presentation: A 70-year-old man was referred for colonoscopy on account of recurrent passage of bloody stool of three months duration. There was no history of anal protrusion, anal pain/discomfort, change in bowel habit, tenesmus, melaena or abdominal pain. No history of fever or weight loss and he had no comorbid illness. He was pale on examination, otherwise other aspects of his general and systemic examinations were normal. At colonoscopy, he had multiple diverticuli in the caecum, ascending colon and descending colon with a sessile polyp in the descending colon. There was a yellowish, oval submucosal sessile mass with a lobulated surface, about $3 \mathrm{~cm}$ from the anal verge and an increased yellowish hue to the large bowel submucosa in the anal canal and at the sites of diverticula. The anal submucosal mass was biopsied.

Conclusion: Lipomas of the anal canal are rare. Although an incidental endoscopic finding in this report, coexistence of large bowel lipomas with increased submucosal adiposis colonic diverticuli may suggest an aetiological role of such lipomas in colonic diverticulosis.
\end{abstract}

\section{Background}

Lipomas are benign adipose tissue tumors commoner between the ages 40-60 years and have a preponderance in the male gender [1]. They may be solitary or multiple, superficial or deep in location and are usually asymptomatic. Cosmetic concerns (in larger lipomas), pain or discomfort are the common indications for removal of superficial lipomas and these commonly occur in the trunk, head and neck regions. Deep-seated lipomas are relatively uncommon; they occur in the thorax, retroperitoneum or abdominal cavity [2]. Intra-abdominal lipomas usually affect the omentum, mesentery, the submucosa and subserosa of the gastrointestinal tract (GIT) [3]. Lipomas are the second most common non-epithelial benign GIT tumours after leiomyomas [4]. The most commonly affected region of the GIT is the colon, with the highest incidence at the cecum, 
ascending colon, transverse colon, and the left colon (in decreasing order as one approaches the rectum) [4]. Occurrence of a lipoma in the anal canal is extremely rare with only one case reported so far by Porta et al in 1979! [5].

In diverticulosis of the colon, there is a transmural outpouching of the colonic mucosa through an area of weakness. This mural weakness-the primary pathology in diverticulosis-is of multifactorial aetiology and the predisposing factors include weakened points of vascular entry into the colonic wall, reduced dietary fiber, hereditary factor, reduced physical activity and obesity [6]. In ventral abdominal wall hernias, stretching of abdominal musculature (because of an increase in its content as seen in obesity) and separation of muscle fibers with weakening of aponeurosis are known to weaken the integrity of the fascia leading to herniation [7]. Whilst the role of mural adipose tissue in the development of GIT diverticula is yet to be established, Yekeler et al have however reported a case of two coexisting rarities- an oesophageal lipoma that resulted in an oesophageal diverticulum due to extramucosal impact of the lipoma [8]. We present an interesting incidental finding of a submucosal anal lipoma in an elderly man who had a concomitant presence of colonic diverticula with an increased submucosal adipose tissue in the vicinity of the diverticuli. This case is reported in line with the SCARE criteria for case reports [9].

\section{Case Presentation}

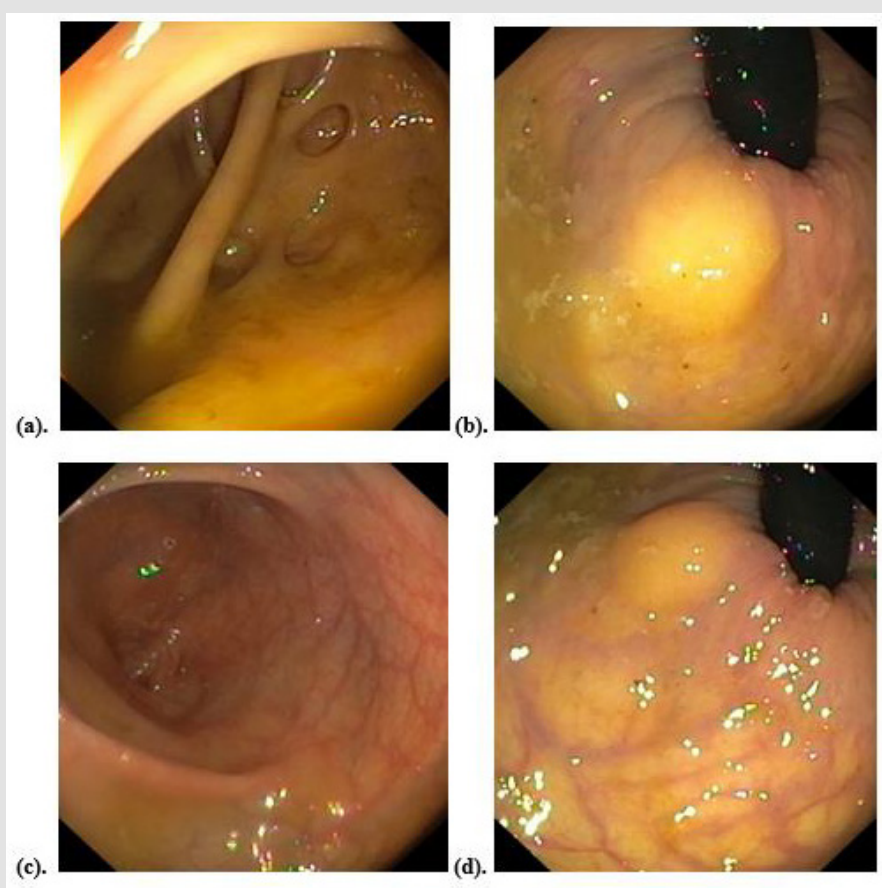

(c).

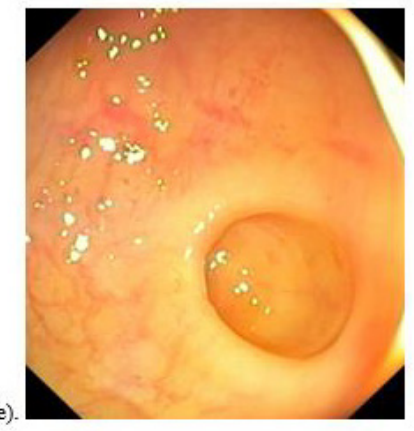

Figure 1: Colonoscopic findings:

a) Caecal diverticuli

b) Yellowish submucosal mass of the anal canal

c) Sigmoid colon mucosa

d) Increased submucosal adipose tissue around anal mass

e) Increased submucosal adipose tissue around a sigmoid colon diverticulum. 
A 70-year-old male retiree was referred for colonoscopy on account of recurrent passage of bloody stool of three months duration, last episode being two weeks earlier. He had no history of anal pain, discomfort, or anal protrusion. There was no change in bowel habit, reduction in stool caliber, melaena, abdominal pain or tenesmus. There was no history of anorexia, haematemesis, early satiety and he does not have a history of peptic ulcer disease. He had no fever, weight loss or any comorbid illness. He had no history of anal trauma or previous anal surgery. No personal or family history of similar illness or malignancy in the past. He was not on any anticoagulation. On examination, he was pale, otherwise other aspects of his general and systemic examinations were normal with a body mass index of $23.1 \mathrm{~kg} / \mathrm{m}^{2}$. A pre-procedural rectal examination did not reveal any abnormality. Colonoscopy revealed multiple diverticuli in the caecum, ascending colon and descending colon (Figure 1a) with a $5 \mathrm{~mm} \times 3 \mathrm{~mm}$ sessile polyp in the descending colon.
There was a yellowish, oval, submucosal sessile mass (about $10 \mathrm{~mm} \times 8 \mathrm{~mm}$ in widest diameters) with a lobulated surface, about $3 \mathrm{~cm}$ from the anal verge (Figure $1 \mathrm{~b}$ ). The mass exhibited positive pillow or cushion sign. The mucosa of the transverse colon, sigmoid colon (Figure 1c) and rectum was normal. However, there was an increased yellowish hue to the large bowel submucosa around the anal canal (Figure 1d) and the sites of diverticula (Figure 1e). No stigmata of recent bleeding were seen. The descending colonic polyp was removed with cold biopsy forceps (Figure 2a). The anal submucosal mass was biopsied revealing the characteristic naked fat sign (Figure 2b). The anal submucosal mass was reported to be benign at histology while the descending colonic polyp was reported as an adenomatous polyp with low grade dysplasia. He has been on conservative care for the colonic diverticulum and has remained asymptomatic both for the diverticulum and the anal submucosal lipoma 3 months post colonoscopy.
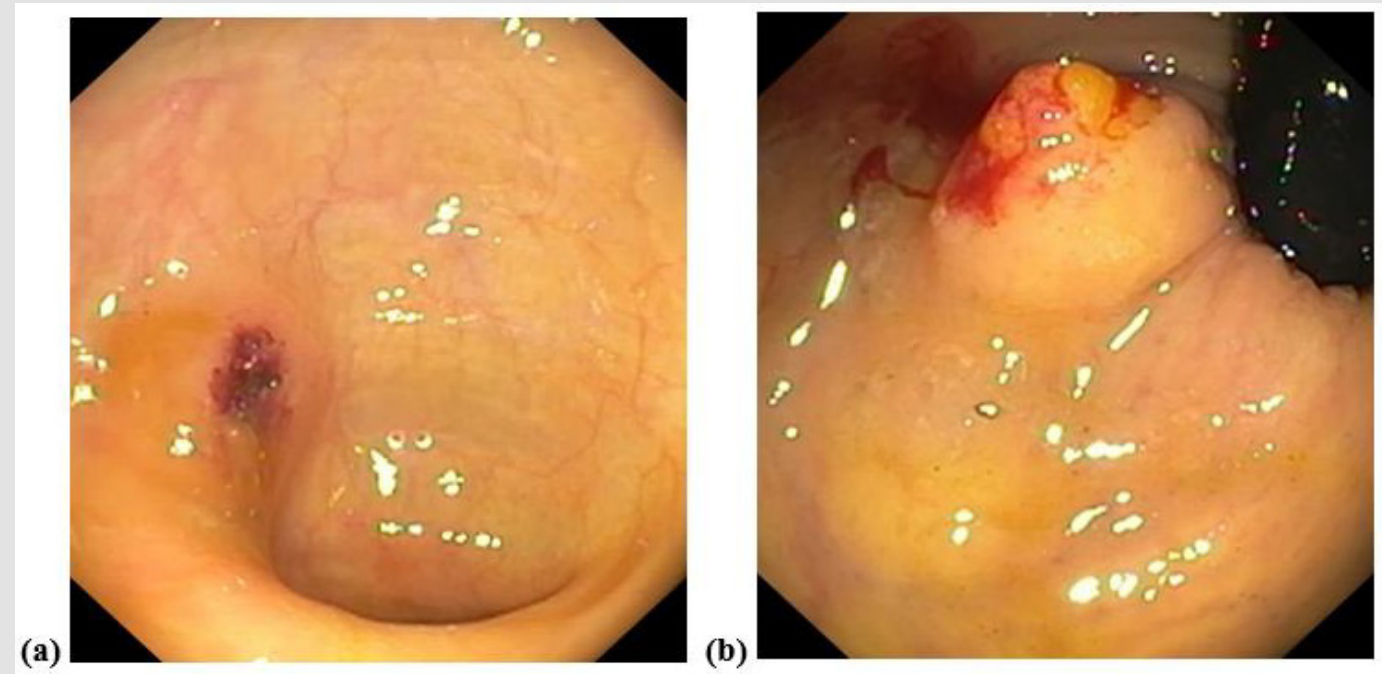

Figure 2:

a) Site of descending colonic polypectomy

b) Anal mass showing spilling out of adipose tissue following biopsy (naked fat sign).

\section{Discussion}

Lipomas are common benign tumour of mature adipose tissue that usually occur in superficial locations - most common location being subcutaneous. The relatively uncommon deep-seated lipomas either present atypically or as incidental findings [10]. In the GIT, they are usually subserosal or submucosal in location, the colon being the most affected region. Involvement of the rest of the large bowel decreases anal-ward. We presented an extremely rare report of a submucosal lipoma of the anal canal with a curious finding of concomitant existence of divertculi at areas of increased submucosal adipose tissue. We discuss this case in terms of rarity and then, its peculiarities. The rarity of this case lies in the fact that it is a deep-seated lipoma occurring in the anal canal. The most distal GIT lipomas reported in the literature are those of the rectum and these presented as polypoid submucosal masses protruding through the anal canal or casuing rectal bleeding [11,12]. Beyond the rectoanal canal, the perianal region, lipomas are also rare with a report of a perianal lipoma occurring years after surgery for a perianal abdscess [13].

The aetiology of the perianal lipoma was likely traumatic, similar to the report by Uscilowska et al on para-anal lipoma resulting from perineal trauma [14]. Beyond trauma, the other 
risk factors for lipoma formation include genetic predisposition, obesity, hyperlipidaemia and diabetes mellitus [15]. There risk factor for lipoma in our patient was not apparent. This was not a surprise since such deep-seated lipomas are incidentalomas like in our patient. Colonic lipomas are usually asymptomatic except when they are larger than $2 \mathrm{~cm}$, torsed, or pendulated. The small size, submucosal location and sessile nature of the lipoma in our patient may explain the asymptomatic nature. The sigmoid colon is said to be the commonest site of colonic diverticulosis, although a study on our patient population by Akere et al revealed right colonic preponderance $[16,17]$ The endoscopic appearance of most colonic diverticuli is that of an outpouching of the mucosa with an otherwise pink-looking mucosa/submucosa due to the rich vasculature of these layers. In diverticulitis, the mucosa of the diverticulum is reddened with or without a surrounding fibrinous slough [18].

The peculiarity of our report is the increased submucoal adiposis in the vicinity of colonic diverticuli, with a predominantly yellowish (than pink) hue to the mucosal color (Figure 1e). These diverticuli involved the caecum, ascending and descending colon with none in the sigmoid colon, the mucosa of which appeared normal (Figure 1c). It therefore stimulates curiosity as to a possible link between increased large bowel mural adiposi and a possible predisposition to subsequent diverticulum formation in the areas where these adipose tissues are located. The plausibility of this link may not be far-fetched if the underlying pathology of colonic diverticulum- mural weakness-is considered. It is therefore more compelling to associate increased submucosal adiposis in our patient with his colonic diverticuli considering the established effect of same adipose tissues on tougher tissues like aponeurosis in abdominal wall hernias. Whilst colonic diverticulosis is commoner in older patients like our patient, Brouland et al reported a large colonic diverticulum in a young male arising due to colonic mural weakness by multiple colonic lipomatosis [19].

The risk factors for colonic diverticulosis include comorbidities (like hypertension and diabetes mellitus), increased luminal pressure (from colonic dysmotility, reduced dietary fiber), genetic risk factors (like Ehlers-Danlos syndrome, Coffin-Lowry and renal polycystic disease), obesity/reduced physical activity, smoking and increasing age [20]. Age alone may not explain the diverticuli seen in our report and none of the other known risk factors was apparent. Although the endoscopic features of the submucosal anal mass we reported were in keeping with a lipoma, histological report did not show the presence of adipocytes. This is a common limitation of endoscopic biopsies where only the mucosal layer is usually biopsied except multiple biopsies are taken at the same spot to include deeper layers. A limitation of this report is our inability to do endoscopic ultrasound which would have confirmed the location of the lipoma. Facility for endoscopic ultrasound is not available in Nigeria as at the time of this report to the best of our understanding.

\section{Conclusion}

Lipomas of the anal canal are rare. Although an incidental endoscopic finding in this report, coexistence of large bowel lipomas with increased submucosal adiposis in the vicinity of colonic diverticuli may suggest an aetiological role of such lipomas in colonic diverticulosis.

\section{Consent}

A written informed consent was obtained from the patient to report this case.

\section{Declaration of Interest}

None.

\section{References}

1. Emegoakor CD, Echezona CN, Onwukamuche ME, Nzeakor HO (2017) Giant lipomas: a report of two cases. Niger J Gen Pract 15: 46-49.

2. Al-Ali MH, Salih AM, Ahmed OF, Kakamad FH, Mohammed SH, et al (2019) Retroperitoneal lipoma: a benign condition with frightening presentation. Int J Case Rep 57: 63-66.

3. Özer M, Ulusoy S, Parlak Ö (2016) A rare location: a giant mesenteric lipoma. Med J Islamic World Acad Sci 24(1): 24-26.

4. Narindra rajaonarison ny ony L, Ahmad A, Bruneton J (2014) Lipomas of the digestive tract: General aspects and imaging. Cureus 6(9): e208.

5. Porta E, Cazzaniga A (1979) Lipoma of the anal canal. Minerva Chir 34(22):1557-1560.

6. Rezapour M, Ali S, Stollman N (2018)Diverticular disease: an update on pathogenesis and management. Gut Liver 12(2): 125-132.

7. Dabbas N, Adams K, Pearson K, Royle GT (2011) Frequency of abdominal wall hernias: is classical teaching out of date? J R Soc Med Sh Rep 2(5): $1-6$.

8. Yekeler E, Yazicioglu A, Subasi M, Boztepe H (2016) Giant oesophageal lipoma as an uncommon cause of diverticula. Case Rep Gatsroenterol 10: 446-451.

9. Agha RA, Borrelli MR, Farwana R, Koshy K, Fowler A, et al. (2018) The SCARE 2018 Statement: Updating Consensus Surgical CAse REport (SCARE) Guidelines. International Journal of Surgery 60: 132-136.

10. Ulasi IB, Afuwape 00, Ajani MA, Onyema AE, Nwadiokwu JI, et al. (2021) A giant pre-peritoneal lipoma: a report of an uncommon presentation of a rare entity and a review of the literature. Surg Case Rep 4(7):1-5.

11. Chakrabarti A, Goenka MK (2016) Submucosal lipoma of the rectum presenting as rectal prolapse and appearing as adenomatous polyp on confocal laser endomicroscopy, a case report and literature review. Gastroenterol Hepatol Open Access 5(1): 6-8.

12. Bagherzade G, Etemad O (2017) Recto-sigmoid lipoma: a case report and review of the literature. J Coloproctol 37(1): 50-54.

13. González-Urquijo M, Zambrano-Lara M, Espinosa-Loera JJ, Gil-Galindo G (2020) Perianal lipoma with an intersphincteric fistula in an adult patient. Rev Gastroenterol Mex (Engl Ed) 85(3): 368-370. 
14. Uscilowska E, Orabi NA, Leonard D, Mourin-Jouret A, Libbrecht L, et al. (2019) Para-anal lipoma as a rare consequence to perineal trauma: case report and review of the literature. Acta Chir Belg 119(6): 390-395.

15. Guler O, Mutlu S, Mahirogullari M (2015) Giant lipoma of the back affecting quality of life. Ann Med Surg 4: 279-282.

16. Perry AF, Keku TO, Martin CF, Eluri S, Runge T, et al. (2016) Distribution and Characteristics of Colonic Diverticula in a United States Screening Population. Clin Gastroenterol Hepatol 14(7): 980-985.

17. Akere A, Ogoh GS, Tejan E (2017) Clinical presentation of patients and distribution of colonic diverticula during colonoscopy at a tertiary hospital in south-west Nigeria. Trop J Health Sci 24(1): 8-12.

ISSN: 2574-1241

DOI: 10.26717/BJSTR.2021.39.006340

Ikechukwu Bartholomew Ulasi. Biomed J Sci \& Tech Res

(C) (P) This work is licensed under Creative

Submission Link: https://biomedres.us/submit-manuscript.php
18. Gross M, Labenz J, Börsch G, Dormann A, Eckardt AJ, et al. (2015) Colonoscopy in acute diverticulitis. Viszeralmedizin 31:124-129.

19. Brouland J, Poupard B, Nemeth J, Valleur P (2000) Lipomatous polyposis of the colon with multiple lipomas of the peritoneal folds and giant diverticulosis: report of a case. Dis Colon Rectum 43(12): 1767-1769.

20. Violi A, Cambie G, Miraglia C, Barchi A, Nouvenne A, et al. (2018) Epidemiology and risk factors for diverticular disease. Acta Biomed 89(9):107-112.

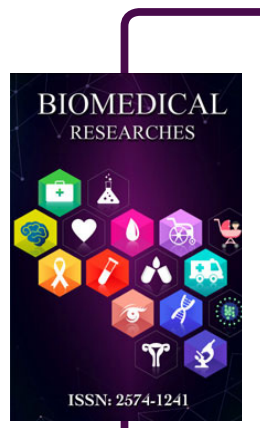

Assets of Publishing with us

- Global archiving of articles

- Immediate, unrestricted online access

- Rigorous Peer Review Process

- Authors Retain Copyrights

- Unique DOI for all articles 